\title{
Corrosion Behavior of Epoxy-Coated Rebar with Pinhole Defect in Seawater Concrete
}

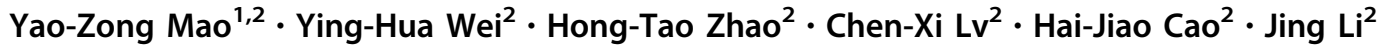

Received: 17 January 2018/Revised: 8 April 2018/Published online: 30 June 2018

(C) The Chinese Society for Metals and Springer-Verlag GmbH Germany, part of Springer Nature 2018

\begin{abstract}
Experiments were carried out to investigate the corrosion behavior of epoxy-coated rebar (ECR) with pinhole defect (diameter in hundreds of microns) immersed in the uncarbonated/carbonated simulated pore solution (SPS) of seawater concrete. Corrosion behavior was analyzed by electrochemical impedance spectroscopy. The composition and morphology of corrosion products were characterized by X-ray diffraction, energy-dispersive spectrometry and scanning electron microscopy. Meanwhile, oxide film produced by preheating before spray coating was investigated by X-ray photoelectron spectroscopy and Mott-Schottky technology. Results indicated that corrosion behavior of ECR with pinhole defect exhibited three stages when immersed in the uncarbonated/carbonated SPS. In the initial stage, steel in defect was passivated when exposed in the uncarbonated SPS and corroded when exposed in the carbonated SPS, due to competitive adsorption between chloride and hydroxyl ions. In the second stage, the oxide film under coating reconstituted (the thickness and defects density decreasing) in the uncarbonated SPS, which was caused by the synergy between high hydroxide and chloride activity, while in the carbonated SPS, crevice corrosion happened under the coating around pinhole, because of the different oxygen concentrations cell at the coating/steel interface. In the third stage, localized corrosion occurred under the coating around the pinhole in the uncarbonated SPS, which was probably induced by ion diffusion at the nano-scale coating/steel interface. The corrosion products adjacent to the defects were re-oxidized from $\mathrm{FeCl}_{2} \cdot 4 \mathrm{H}_{2} \mathrm{O}$ and $\mathrm{Fe}_{2}(\mathrm{OH})_{3} \mathrm{Cl}$ to $\mathrm{Fe}_{2} \mathrm{O}_{3} \cdot \mathrm{H}_{2} \mathrm{O}$, and the corrosion area was expanded outward in the carbonated SPS.
\end{abstract}

Keywords Corrosion $\cdot$ Epoxy-coated rebar $($ ECR) $\cdot$ Seawater concrete $\cdot$ Pinhole defects

\section{Introduction}

Replacing fresh water with seawater during the construction of concrete structure in coastal areas will largely reduce the cost of transportation and increase the work efficiency. It would be very convenient and economical in construction, especially in pelagic work. However, the use of seawater is impeded in most of the reinforced concrete standards, considering the risk of early corrosion of reinforcement induced by chloride ions in seawater compounds

Available online at http://link.springer.com/journal/40195

Ying-Hua Wei

yhwei@imr.ac.cn

1 School of Materials Science and Engineering, University of Science and Technology of China, Hefei 230026, China

2 Institute of Metal Research, Chinese Academy of Sciences, Shenyang 110016, China
$[1,2]$. The epoxy-coated rebar (ECR) has been widely used to control the corrosion of steel reinforcing bars in the marine infrastructure. The epoxy is usually a bisphenolamine formulation, applied with electrostatic spray guns and cured at high temperature [3], and ECR was regarded as a kind of cost-effective method for increasing the service life of reinforced structures. And it has been reported to have good performance, due to its low permeability to chloride ions, high alkaline resistance and good adhesion to steel. However, some studies have suggested that the effectiveness of ECR was limited [4], including the corrosion of ECR in concrete in subtropical marine environments. For instance, early severe corrosion of ECR was observed in the substructure of five major bridges in the Florida Keys, leading to the reinforced concrete cracking and spalling [5, 6]. The associated corrosion processes have been extensively investigated in both the laboratory and field. Based on the results of investigation, the problem was considered to be attributed to defects or sites of damage 
that were aggravated by fabrication, handling, or severe yard construction environment in coating. The mechanisms for the corrosion of ECR caused by defects in the marine environment have been extensively studied. For instance, Sagues et al. [7, 8] suggested that the corroded ECR was caused by the development of corrosion macrocell at defects when chloride ions arrived, and the accumulation of corrosion products under the coating led to coating breakdown [9]. Jr et al. [10] found that the cathode areas reduced the coating/steel adhesion in the region further away from the defect due to the penetration of concrete pore solution, resulting in disruption around the defects or blisters near the defect [11]. Zhong et al. [12] have studied corrosion of steel under defected coating in various solutions using in situ detection technology, such as localized electrochemical impedance spectroscopy (LEIS), scanning Kelvin probe (SKP) providing an essential technique to microscopically characterize the local electrochemical corrosion reaction of steel under the defected coating. Their experiments showed that corrosion process at the defect sites depended on the size of the defect, and the corrosion behavior under coating was controlled by the oxygen partial pressure [13] and defect geometry [14].

Many studies have shown that anodic blistering was attributed to localized corrosion under the coating followed by blistering via an osmotic pressure mechanism [15], and the cathodic delamination was probably induced by the alkaline cathodic reaction products [16]. The current polarity may be conversed in the site of the defect and the steel under the coating $[17,18]$.

Most previous studies focused on concrete mixed with fresh water, but it has been not clear about corrosion behavior of defected ECR in seawater concrete. Meanwhile, the ratio of $\mathrm{Cl}^{-} / \mathrm{OH}^{-}$is an important factor impacting the rebar corrosion behavior. Some researchers found that the addition of chlorides would not cause corrosion if the ratio of $\mathrm{Cl}^{-} / \mathrm{OH}^{-}$did not exceed its threshold $[19,20]$. When the rebar is embedded in seawater concrete with high alkalinity of pore solution, it might be secured. Conversely, the loss of alkalinity due to carbonation of the concrete would result in rebar breakdown. Therefore, it is important to study corrosion behavior and process of defected ECR in seawater concrete in both carbonated and uncarbonated conditions. Elucidating corrosion mechanism will be significantly useful to provide effective protection methods.

The purpose of this work is to provide a better understanding of the degradation behavior of pinhole-defected ECR embedded in seawater concrete. Specifically, this work presents the corrosion mechanism and mode of pinhole-defected ECR immersed in uncarbonated and carbonated seawater concrete pore solution with $\mathrm{pH} 13.4$ and 9.8 , containing $0.6 \mathrm{~mol} / \mathrm{L}$ ( $3.5 \%$ by mass) sodium chloride.
This work will help polymer-coated producers to design better coating/steel rebar system applied in the reinforced concrete mixed with seawater, and provide some fundamental knowledge for appropriate corrosion protection in the field.

\section{Experimental}

\subsection{Materials}

The chemical composition of the reinforcing steel bar was $0.22 \mathrm{C}, 0.43 \mathrm{Si}, 1.25 \mathrm{Mn}, 0.017 \mathrm{P}, 0.02 \mathrm{~S}, 0.03 \mathrm{Cr}, 0.02 \mathrm{Ni}$, $0.02 \mathrm{Cu}, 0.035 \mathrm{~V}$, balance $\mathrm{Fe}(\mathrm{wt} \%)$. The specimens with a surface area of $10 \mathrm{~mm} \times 10 \mathrm{~mm}$ were cut from the reinforcing steel bar. The working electrode surface was grit blasted and rinsed with distilled water, dried with compressed air, and cleaned with ethanol before coating. The fusion-bonded epoxy used in this investigation was provided by Institute of Metal Research, Chinese Academy of Sciences.

\subsection{Preparation of Coated Specimens}

In spraying process, the specimens were heated to $240{ }^{\circ} \mathrm{C}$ for $15 \mathrm{~min}$, and then electrostatically sprayed with the powder epoxy coating, and cured at $230 \pm 2{ }^{\circ} \mathrm{C}$ for 20 min. A preliminary experiment indicated that these conditions produced well-cured films. The thicknesses of the coatings were controlled by the number of times the electrostatic gun passed over a panel, and then measured by thickness gauge. Only the specimens falling in $250 \pm 20 \mu \mathrm{m}$ were used. Coated specimens were tested for holidays using a holiday detector, and the specimens containing holidays were excluded from this study. Finally, the back of the specimens were welded to a conducting wire for electrochemical measurement. Besides the coating, the other surfaces of the sample were embedded in polyvinyl chloride holder using epoxy resin to prevent corrosion. The pinhole defects with 200,500 or $800 \mu \mathrm{m}$ in diameter were made, respectively, for the experiment using the microdrill after the epoxy resin cured completely.

\subsection{Experimental Condition}

The experimental medium was simulated pore solution (SPS) of uncarbonated and carbonated seawater concrete. The composition and $\mathrm{pH}$ of them are provided in Table 1 . Each experiment was carried out at temperature of $25^{\circ} \mathrm{C}$, and the solution was replaced with fresh solution each week. The $\mathrm{pH}$ of solution was monitored frequently to keep the variance less than \pm 0.3 . 
Table 1 Composition and $\mathrm{pH}$ of simulated pore solution

\begin{tabular}{lllllrr}
\hline Solution & $\mathrm{KOH}(\mathrm{mol} / \mathrm{L})$ & $\mathrm{NaOH}(\mathrm{mol} / \mathrm{L})$ & $\mathrm{NaHCO}_{3}(\mathrm{~mol} / \mathrm{L})$ & $\mathrm{Na}_{2} \mathrm{CO}_{3}(\mathrm{~mol} / \mathrm{L})$ & $\mathrm{NaCl}(\mathrm{mol} / \mathrm{L})$ & $\mathrm{pH}$ \\
\hline Uncarbonated & 0.6 & 0.2 & 0 & 0 & 0.6 & 13.4 \\
Carbonated & 0 & 0 & 0.06 & 0.04 & 0.6 & 9.8 \\
\hline
\end{tabular}

\subsection{Corrosion Behavior Test}

Electrochemical measurements were performed with a three-electrode cell through a PAR273A electrochemical work station. It comprises a potentiostat/galvanostat with lock-in amplifier 5210. Electrochemical impedance spectroscopy (EIS) used a traditional three-electrode system as shown in Fig. 1. The specimen with an exposure area of $1.0 \mathrm{~cm}^{2}$ was used as the working electrode. A saturated calomel electrode (SCE) was used as the reference electrode and placed in a Luggin probe to avoid any disturbation from solution. A platinum sheet $(15 \mathrm{~mm} \times 15 \mathrm{~mm})$ was used as the counter electrode. EIS spectra were acquired at the open-circuit potential (OCP) over the frequency range of $100 \mathrm{kHz}$ to $10 \mathrm{mHz}$ using an alternating current signal amplitude of $10 \mathrm{mV}$ (root mean square, rms). The results of EIS measurements were analyzed by the Zsimpwin software. Validation of the spectra were performed by several means including checking the stability of the system, i.e., measuring the spectra at AC signal amplitudes between 2 and $20 \mathrm{mV}$ (rms), as well as the

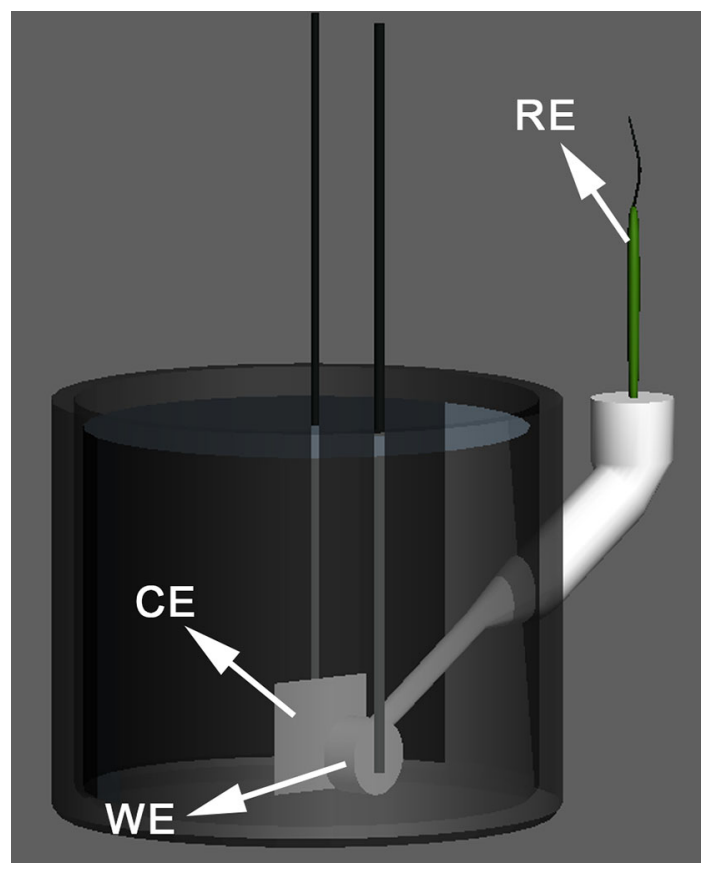

Fig. 1 Schematic illustration of three-electrode cell for electrochemical test (RE: reference electrode; CE: counter electrode; WE: work electrode)
Kramers-Kronig $(\mathrm{K}-\mathrm{K})$ transform test based on the procedure of Boukamp. Meanwhile, Mott-Schottky measurements were performed at single frequency of $1 \mathrm{kHz}$ in the potential range from -1200 to $800 \mathrm{mV}$ at $25{ }^{\circ} \mathrm{C}$, and a high potential sweep rate of $50 \mathrm{mV} / \mathrm{s}$ was used.

\subsection{Microstructure and Chemical Analyses}

The morphology and elemental composition of the corrosion product exposed surface were characterized by a scanning electron microscopy (SEM, Philips FEG XL30), when the coating of specimens was removed away using acetone. The phase structures of the samples were carried out on a Bruker D8 DISCOVER with two-dimensional detector VANTEC500, and the X-ray wavelength was $0.179 \mathrm{~nm}$ and diffraction beam diameter was $0.5 \mathrm{~mm}$. X-ray photoelectron spectroscopy (XPS) experiments were performed on the samples surfaces before and after sputtering by Thermo VG ESCALAB 250, using an Al anode and non-monochromatic radiation. The spectra were taken in Constant Analyzer Energy (CAE) mode (30 eV).

\section{Results and Discussion}

The experimental results showed that the actual corrosion behaviors of ECR with pinhole defect immersed in uncarbonated and carbonated seawater concrete pore solution were different, but both of them exhibited three stages. Furthermore, the steel corrosion behavior depended on not only the $\mathrm{pH}$ of situation and immersion time but also the size of the defect.

\subsection{OCP-Time Measurements}

The change of OCP versus time was performed before EIS measurements, although OCP-time behavior is influenced by the complicated SPS solution, such as oxygen concentration, temperature, humidity. Leelalerkiet et al. [21] and Ohtsu and Yamamoto [22] suggested that the half-cell potential measurement without compensation may be unreliable. However, the trend of the OCP-time has reference significance for the corrosion behavior of the steel. The result proved that the OCP of ECR with pinhole defect increased rapidly at the early stage and stabilized between 
-0.1 and $-0.2 V_{\mathrm{SCE}}$ in the uncarbonated SPS shown in Fig. 2a. Meanwhile, the carbonated SPS of seawater concrete led to a shift in OCP to the negative direction, which decreased rapidly and kept from -0.5 to $-0.7 V_{\mathrm{SCE}}$ shown in Fig. 2b. It was possibly caused by the competitive adsorption between chloride and hydroxyl ions at the pinhole sites. The hydroxide mechanism tended to prevail over the chloride mechanism because of the high hydroxide activity and high alkalinity [23] in the uncarbonated SPS, which induced the steel passivation at the pinhole sites and resulted in the increased OCP. Contrarily, the steel at the pinhole sites was corroded when immersed in carbonated SPS and resulted in the decreased OCP.

\subsection{EIS and Coating/Steel Interface Test Results}

EIS was employed to investigate the corrosion performance of various specimens. The electrical and electrochemical behaviors of such system can be represented by equivalent circuit models at different stages.

During the early stage of the experiment (i.e., $24 \mathrm{~h}$ ), it indicated from Nyquist plots (Fig. 3a, c) that all of the ECR with different sizes of pinhole defects showed a similar feature, which was composed with one semicircular arc. Two frequency-dependent time constants could be observed from the bode phase angle plots (Fig. 3b, d), when the specimens were immersed in uncarbonated and carbonated SPS. It was the typical impedance behavior as that measured on the steel under a degraded coating $[24,25]$. The time constant at high-frequency range was associated with the coating capacitance and pore resistance in pinhole defect, while the low-frequency time constant was the response corresponding to the corrosion reaction occurred at the defect sites as the solutions passed through the pinhole to the substrate. The equivalent electrical circuit was used to simulate the electrochemical behavior of the reaction process at this stage shown in Fig. 4a, which was analyzed using Zsimpwin software and the most suitable model (the smallest Chi-square values). The fitted lines were presented along with the measured data in points. In this model, $R_{\mathrm{S}}$ represented the solution resistance, while $R_{0}$ and $C_{\mathrm{f}}$ corresponded to the pore resistance in pinhole defect and coating capacitance, respectively. $R_{\mathrm{ct}}$ and $\mathrm{CPE}_{\mathrm{dl}}$ were the charge transfer resistance and doublelayer capacitance of the system, respectively.

After immersed in uncarbonated SPS for 3 days, all of the ECR with pinhole defect had a single semicircle at Nyquist diagram shown in Fig. 5a. However, bode phase diagram could be divided into three parts corresponding to three frequency-dependent time constants in the uncarbonated SPS shown in Fig. 5b. Similarly, the time constant in high frequency corresponded to coating capacitive and pore resistance in the pinhole defect. One of the time constants in low-frequency range indicated that the oxide film was produced by preheating on the substrate before spray coating. And another was the charge transfer resistance and double-layer capacitance between the coating and the substrate when chloride and hydroxide ions migrated along the coating/steel interface from the defect sites to the inner with solution. The corresponding reactions were confirmed by the XPS and Mott-Schottky measurements.

XPS and the $\mathrm{Ar}^{+}$beam etching were used to analyze the element existence state and the change of the oxide film thickness with the immersion time. After heated at $230{ }^{\circ} \mathrm{C}$ for $20 \mathrm{~min}$, the XPS depth etch chart of the oxide film on the substrate changed with different immersion time as shown in Fig. 6a. The preheated specimen before immersion was named $\mathrm{F}-\mathrm{Oh}$, after $\mathrm{Ar}^{+}$beam sputtering on its surface for about $350 \mathrm{~s}$, the oxygen atom content has
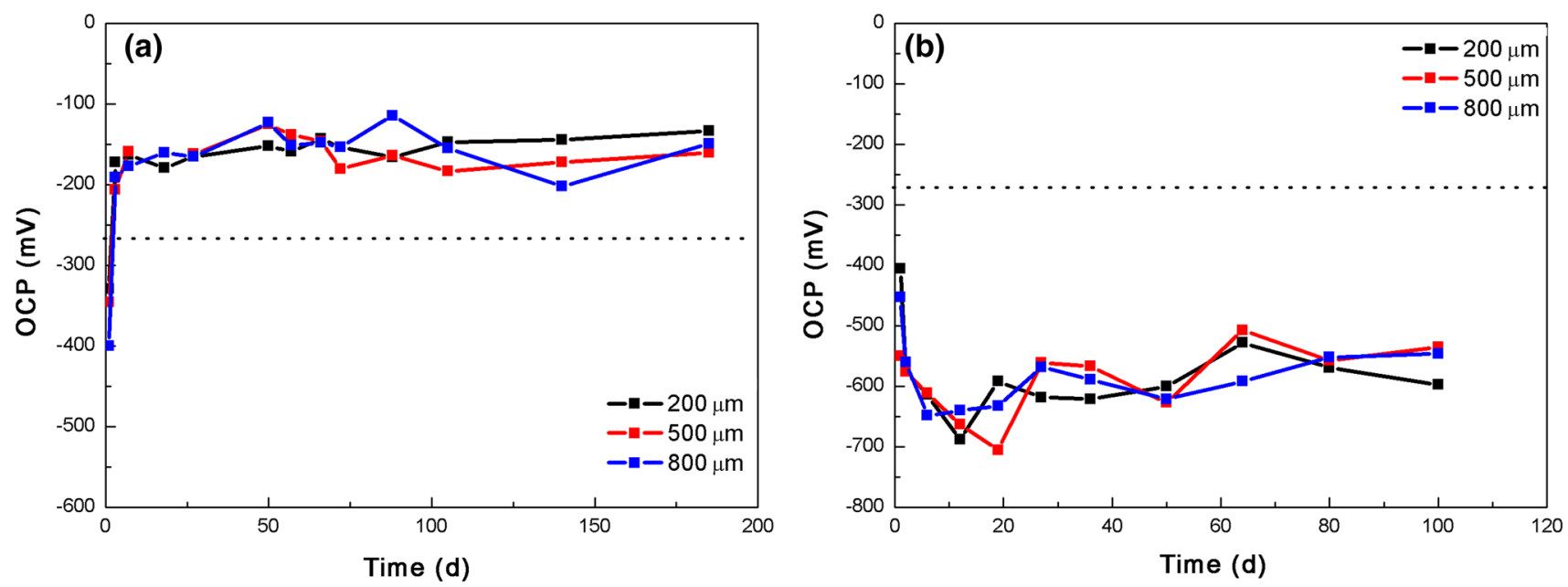

Fig. 2 OCP-time curves of defected ECR in seawater concrete: a uncarbonated SPS; $\mathbf{b}$ carbonated SPS 

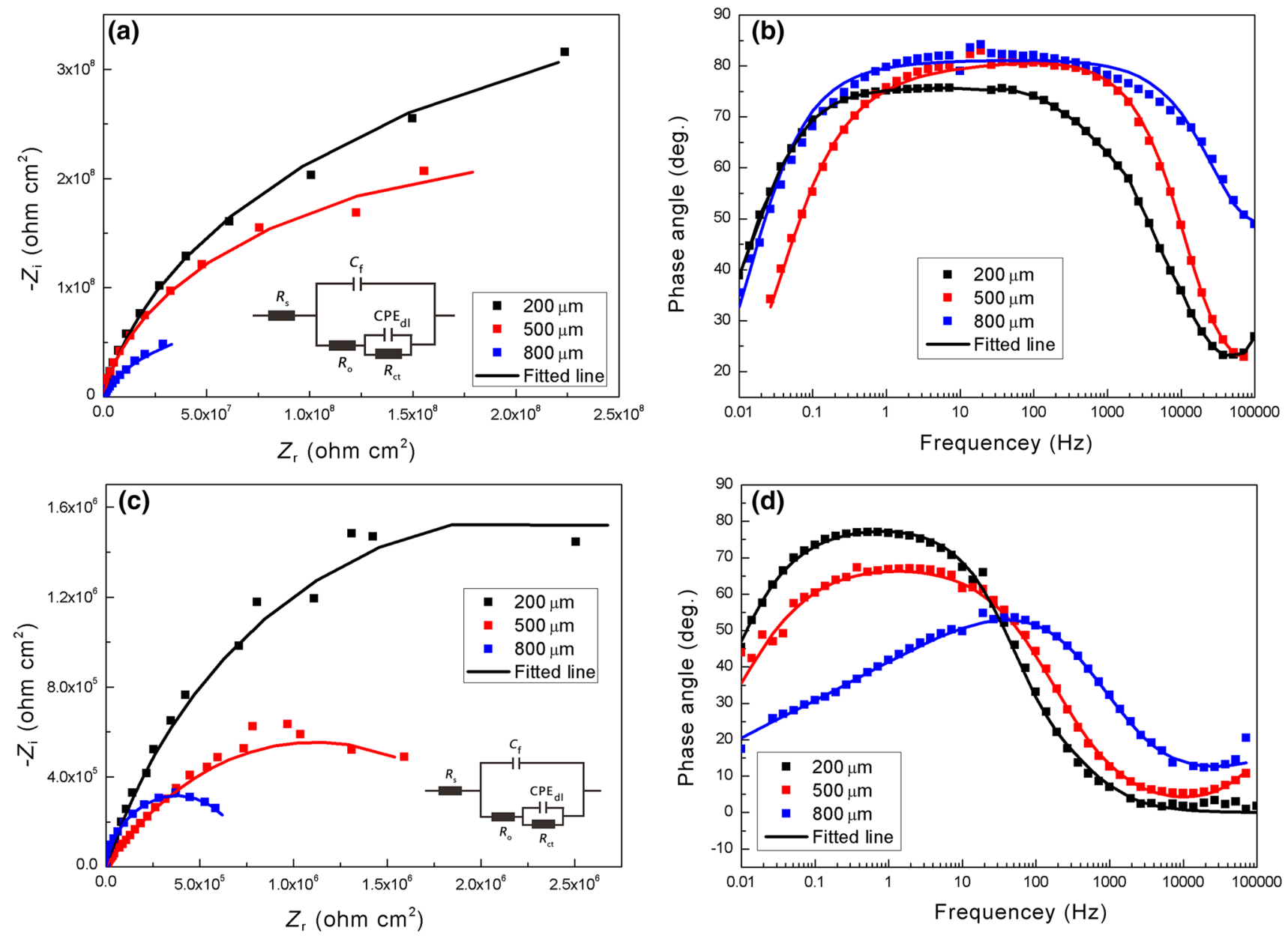

Fig. 3 Nyquist $(\mathbf{a}, \mathbf{c})$ and Bode $(\mathbf{b}, \mathbf{d})$ plots of defected ECR and corresponding fitting results of EIS data after immersion for $24 \mathrm{~h}$ in uncarbonated $(\mathbf{a}, \mathbf{b})$; carbonated $(\mathbf{c}, \mathbf{d}) \operatorname{SPS}\left(Z_{\mathrm{r}}\right.$ : real part of impedance; $Z_{\mathrm{i}}$ : imaginary part of impedance)

(a)

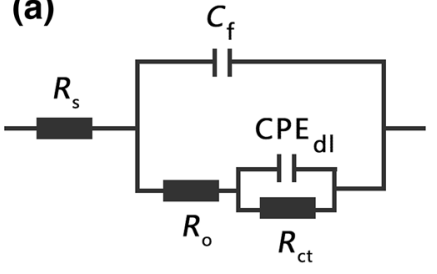

(b)

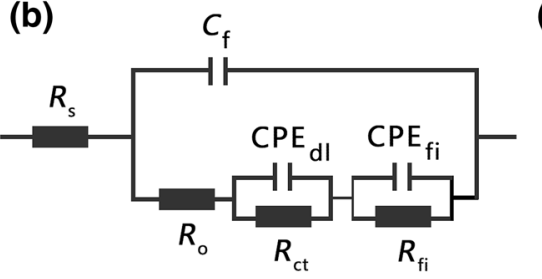

(c)

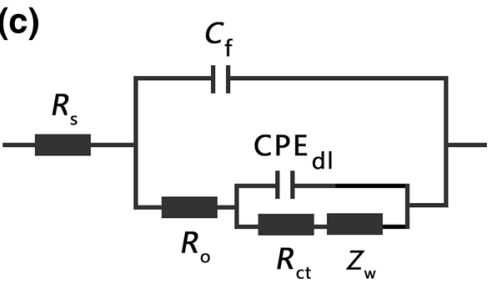

Fig. 4 Equivalent circuit models used to fit the EIS data of defected ECR at different stages: a first stage; $\mathbf{b}$ second stage; $\mathbf{c}$ third stage $\left(R_{\mathrm{s}}\right.$ : solution resistance; $R_{0}$ and $C_{\mathrm{f}}$ : pore resistance in pinhole defect and coating capacitance, respectively; $R_{\mathrm{ct}}$ and $\mathrm{CPE}_{\mathrm{dl}}:$ charge transfer resistance and double-layer capacitance, respectively; $R_{\mathrm{fi}}$ and $\mathrm{CPE}_{\mathrm{fi}}$ : oxide film resistance and capacitance, respectively; $Z_{\mathrm{w}}$ : Warburg impedance)

become to $0 \%$ basically, indicating that $\mathrm{Ar}^{+}$beam has been completely reached the matrix. For the specimens named as F-2d and F-7d that were immersed in uncarbonated SPS for about 2 and 7 days, it would take about $200 \mathrm{~s}$ to reach the matrix completely. The passive film formed on unpreheated steel after 2 days (L-2d) immersed in uncarbonated SPS disappeared substantially after $100 \mathrm{~s}$ of $\mathrm{Ar}^{+}$ beam sputtering. The rate of $\mathrm{Ar}^{+}$beam sputtering was about $0.1 \mathrm{~nm} / \mathrm{s}$, and the thicknesses of the oxide film were $15-20 \mathrm{~nm}$ for F-0h, $8-10 \mathrm{~nm}$ for F-2d and F-7d, and
4-5 $\mathrm{nm}$ for L-2d. The results confirmed that the oxide film became thinner after immersion.

Previous studies indicated that the oxidation state of $\mathrm{Fe}$ could be determined by analyzing the binding energy of $\mathrm{Fe}$ 2p3/2 [26-29]. The peak of $\mathrm{Fe} 2 p$ binding energy in $\mathrm{Fe}_{2} \mathrm{O}_{3}$ was about $711 \mathrm{eV}$, and $\mathrm{Fe}^{3+}$ satellite peak appeared at about $719 \mathrm{eV}$. The $\mathrm{Fe} 2 p 3 / 2$ peak and $\mathrm{Fe}^{2+}$ satellite in $\mathrm{Fe}_{3} \mathrm{O}_{4}$ were about 710 and $716 \mathrm{eV}$, respectively. $\mathrm{Fe}$ $2 p$ XPS spectra on the surface of the specimens (F-Oh, F-2d, L-2d) without $\mathrm{Ar}^{+}$beam sputtering are shown in 

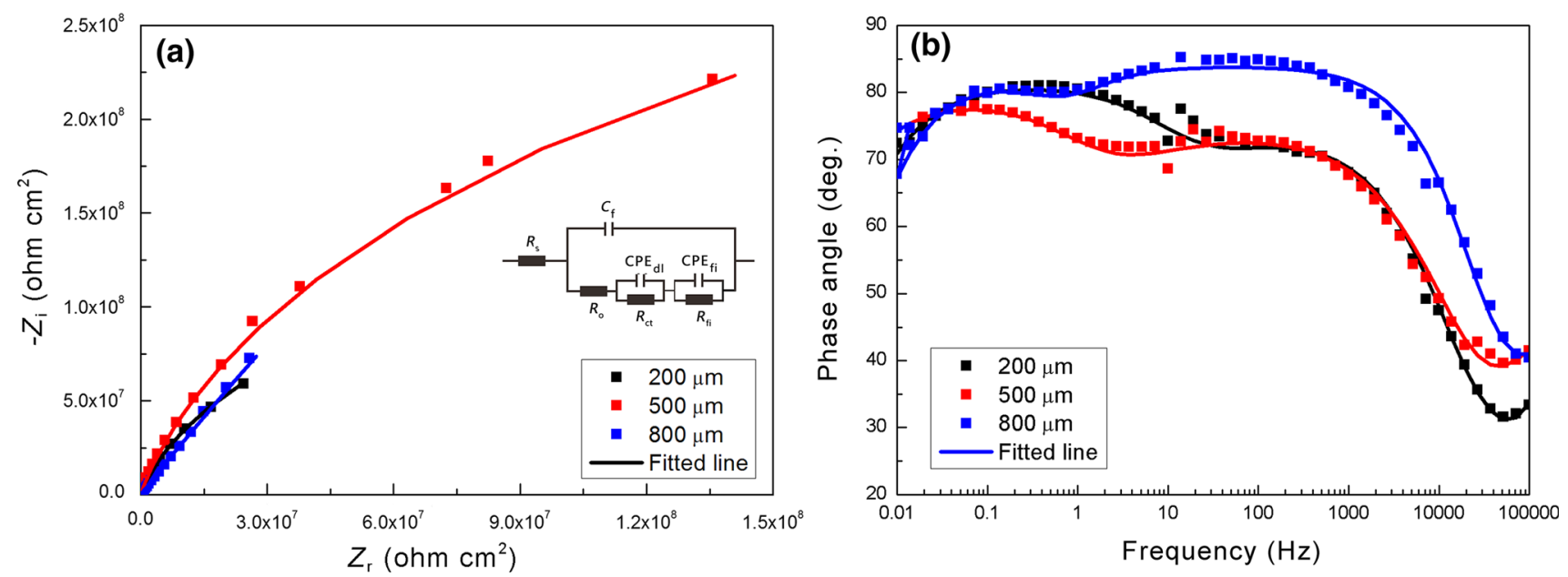

Fig. 5 Nyquist (a) and Bode (b) plots of defected ECR immersed in uncarbonated SPS for 3 days and corresponding fitting results of EIS data
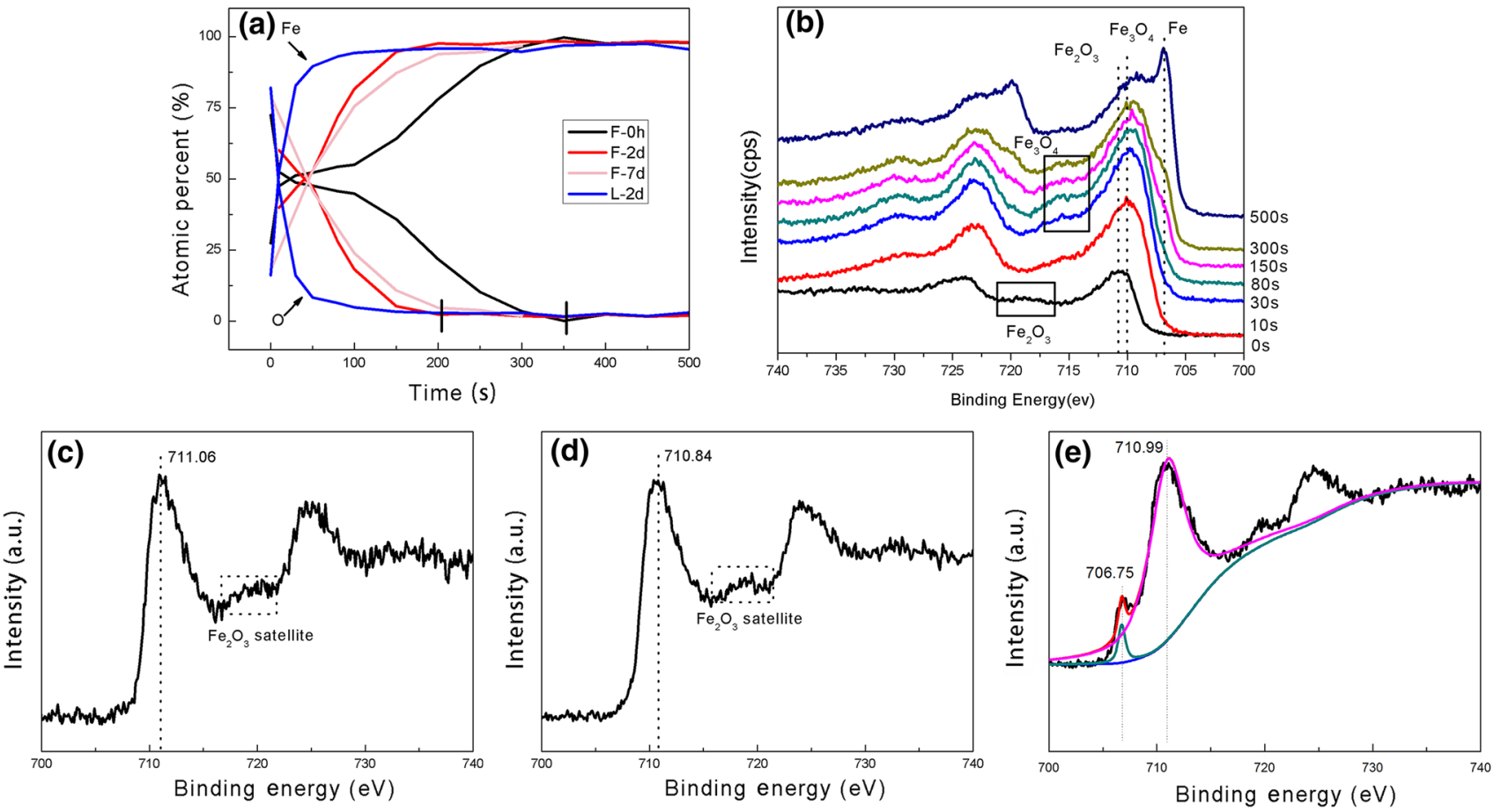

Fig. 6 XPS graphs of substrate surface under different conditions immersed in uncarbonated SPS: a XPS depth etching diagram; b XPS spectra of $\mathrm{Fe} 2 p$ on steel surface for preheating $20 \mathrm{~min}$ by $\mathrm{Ar}^{+}$sputtering for different time; c-e XPS spectra of Fe $2 p$ on surface of F-0h, F-2d, L-2d, respectively

Fig. 6c-e, which indicated that the oxidation states of Fe were $\mathrm{Fe}(\mathrm{III})$ before and after immersion. In addition, there was a little of iron presented in unpreheated steel due to incomplete passivation. Fe $2 p$ XPS spectra on the steel surface for preheating $20 \mathrm{~min}$ after being sputtered by $\mathrm{Ar}^{+}$ sputtering for different time are shown in Fig. 6b. As the sputtering time of $\mathrm{Ar}^{+}$prolonged, the $\mathrm{Fe} 2 p 3 / 2$ peak gradually moved to the low energy direction. After $30 \mathrm{~s}$ of $\mathrm{Ar}^{+}$sputtering, the $\mathrm{Fe} 2 p$ pattern of $\mathrm{Fe}_{3} \mathrm{O}_{4}$ and $\mathrm{Fe}^{2+}$ satellite peak appeared which indicated that the oxide film was mainly composed of $\mathrm{Fe}_{2} \mathrm{O}_{3}$ and $\mathrm{Fe}_{3} \mathrm{O}_{4}$.

The capacitance $\left(C_{\mathrm{sc}}\right)$ of the oxide film polarized at potentials where the states depleted could be expressed by the Mott-Schottky (M-S) equation [30, 31]:

$C_{\mathrm{sc}}^{-2}=\frac{2}{\varepsilon \varepsilon_{0} q N_{q}}\left(E_{\mathrm{FB}}-E+\frac{k T}{e}\right)$.

where $N_{\mathrm{q}}$ is the doping density, representing the donor $N_{\mathrm{d}}$, or acceptor $N_{\mathrm{a}}$ densities for a n-type or a p-type 
semiconductor, respectively, $\varepsilon$ is the dielectric constant of the oxide film, $\varepsilon_{0}$ is vacuum permittivity, $q$ is the elementary charge, $k$ is the Boltzmann constant, $T$ is the temperature $(K), e$ is electron charge $\left(1.6 \times 10^{-19} \mathrm{C}\right), E$ is the applied potential $\left(V_{\mathrm{SHE}}\right)$, and $E_{\mathrm{FB}}$ is the flat band potential.

It could be seen from the preheated specimen measured at different immersion time as shown in Fig. 7, that the M$\mathrm{S}$ curve slopes were positive, corresponding to n-type semiconductor characteristics. At the same time, the slopes of the $\mathrm{M}-\mathrm{S}$ curve increased with the immersion time, which confirmed that the donor density of the matrix oxide decreased with the extension of the immersing time, and the crystal defects in the oxide film were also reduced [32].

Thickness of the oxide film decreased from 15-20 nm to $8-10 \mathrm{~nm}$ in the uncarbonated SPS, and the density of the defects in the oxide film reduced simultaneously. Both of them indicated that some reactions indeed happened on the oxide film. Comparing the XPS spectra of $\mathrm{Fe} 2 p$ on the steel surface, we found that all of the constitutions were $\mathrm{Fe}_{2} \mathrm{O}_{3}$ among steels immersed for $0 \mathrm{~h}, 48 \mathrm{~h}$ and unpreheated steel immersed for $48 \mathrm{~h}$. We proposed that the oxide film produced during the preheating of the steel was reconstituted under the coating, and the principal reactions included as followed:

$\mathrm{Fe}_{2} \mathrm{O}_{3}+6 \mathrm{Cl}^{-}+3 \mathrm{H}_{2} \mathrm{O} \rightarrow 2 \mathrm{FeCl}_{3}+6 \mathrm{OH}^{-}$,

$2 \mathrm{Fe}_{3} \mathrm{O}_{4}+18 \mathrm{Cl}^{-}+\frac{1}{2} \mathrm{O}_{2}+9 \mathrm{H}_{2} \mathrm{O} \rightarrow 6 \mathrm{FeCl}_{3}+18 \mathrm{OH}^{-}$,

$2 \mathrm{FeCl}_{3}+6 \mathrm{OH}^{-} \rightarrow \mathrm{Fe}_{2} \mathrm{O}_{3}+6 \mathrm{Cl}^{-}+3 \mathrm{H}_{2} \mathrm{O}$.

The oxide film was dissolved by chloride ions that migrated continually from bulk solution. However, due to the presence of high concentrations of hydroxyl ions around, the free states of iron ions produced by reactions

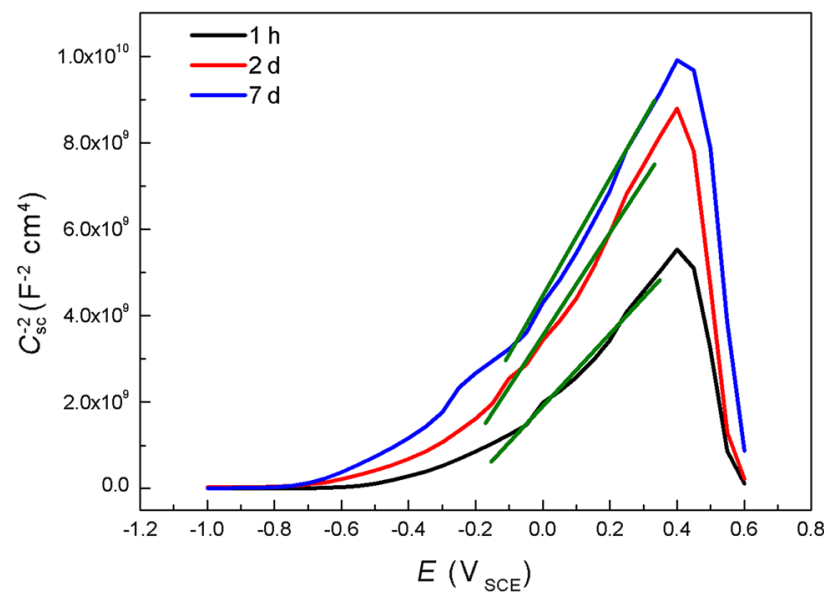

Fig. 7 Mott-Schttoky curves for preheated steel at different immersion time
(2) and (3) were re-passivated though reaction (4) rather than further corrosion. The equivalent electrical circuit was used to fit the measured data shown in Fig. $4 \mathrm{~b}$, and the fitted line was presented along with the measured data in points. $R_{\mathrm{ct}}$ and $\mathrm{CPE}_{\mathrm{dl}}$ correspond to the resistance and capacitance of the double layer between the coating and the substrate, respectively. $R_{\mathrm{fi}}$ and $\mathrm{CPE}_{\mathrm{fi}}$ correspond to the resistance and capacitance of oxide film produced at preheating on the substrate and passivated at the first stage.

When the specimens were immersed in carbonated SPS for 3 days, the Nyquist plot of $200 \mu \mathrm{m}$ defect contained a straight line with an approximate $45^{\circ}$ slope in the lowfrequency range shown in Fig. $8 \mathrm{a}$, and three frequencydependent time constants appeared in the bode phase diagrams shown in Fig. 8b.

The straight line with a slope close to $45^{\circ}$ in the lowfrequency range was a Warburg diffusive impedance [33]. The overlap of Warburg impedance with a semicircle in the low-frequency range showed that the diffusion process contributed to the whole corrosion reaction at the base of the defect. This phenomenon was primarily due to the small size of the defect and the narrow interface between the coating and substrate [12]. The equivalent electrical circuit was used to fit the measured data shown in Fig. 4c. $R_{\mathrm{ct}}$ and $\mathrm{CPE}_{\mathrm{dl}}$ correspond to the resistance and capacitance of the double layer at the corrosion reaction on the steel. However, when the coating contained relatively big pinholes, such as the defect with 500 or $800 \mu \mathrm{m}$, there was a common feature for EIS plots like the first stage, and the Warburg impedance did not appear. Because of the relatively bigger size of the defect, the electrolyte could reach the steel surface rapidly. The measured data can be fitted by the equivalent electrical circuit shown in Fig. 4a.

When the coating of the specimens immersed in carbonated SPS was removed, a typical crevice corrosion phenomenon was revealed around the pinhole defect shown in Fig. 9c. Oxygen absorption occurred in the anterior segment of the gap close to the pinhole defect due to the sufficient oxygen supply, according to the following reaction:

$\frac{1}{2} \mathrm{O}_{2}+\mathrm{H}_{2} \mathrm{O}+2 \mathrm{e}^{-} \rightarrow 2 \mathrm{OH}^{-}$.

In the gap away from the pinhole defect where the oxygen concentration was low, corrosive medium reacted with base metal and caused the substrate anode dissolution. The principal corrosion reactions of iron that took place in a saline aqueous environment at the anodic sites under the coating included as followed [15]:

$\mathrm{Fe} \cdot \mathrm{H}_{2} \mathrm{O}_{\text {ads }}+\mathrm{Cl}^{-} \rightarrow \mathrm{FeCl}_{\text {ads }}^{-}+\mathrm{H}_{2} \mathrm{O}$,

$\mathrm{FeCl}_{\text {ads }}^{-}+\mathrm{H}_{2} \mathrm{O} \rightarrow \mathrm{FeOH}^{+}+\mathrm{Cl}^{-}+\mathrm{e}^{-}$,

$\mathrm{FeOH}^{+}+\mathrm{H}^{+} \rightarrow \mathrm{Fe}^{2+}+\mathrm{H}_{2} \mathrm{O}$. 

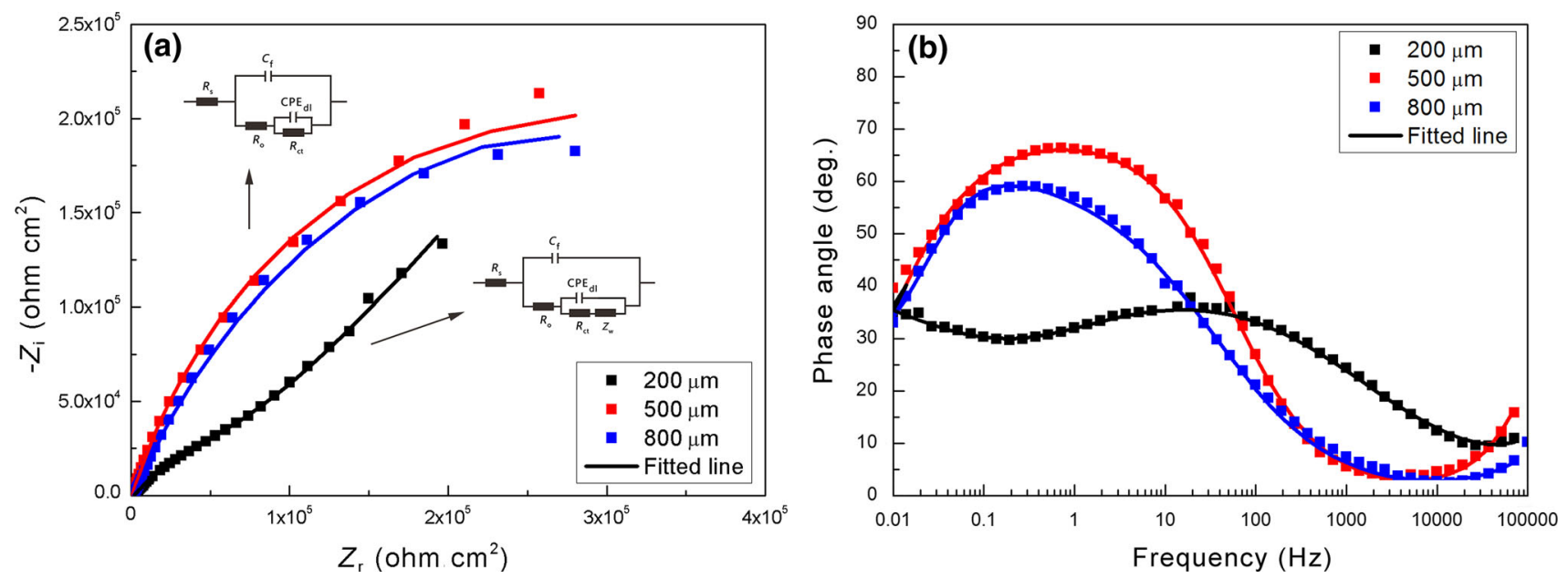

Fig. 8 Nyquist (a) and Bode (b) plots of defected ECR immersed in carbonated SPS for 3 days and corresponding fitting results of EIS data
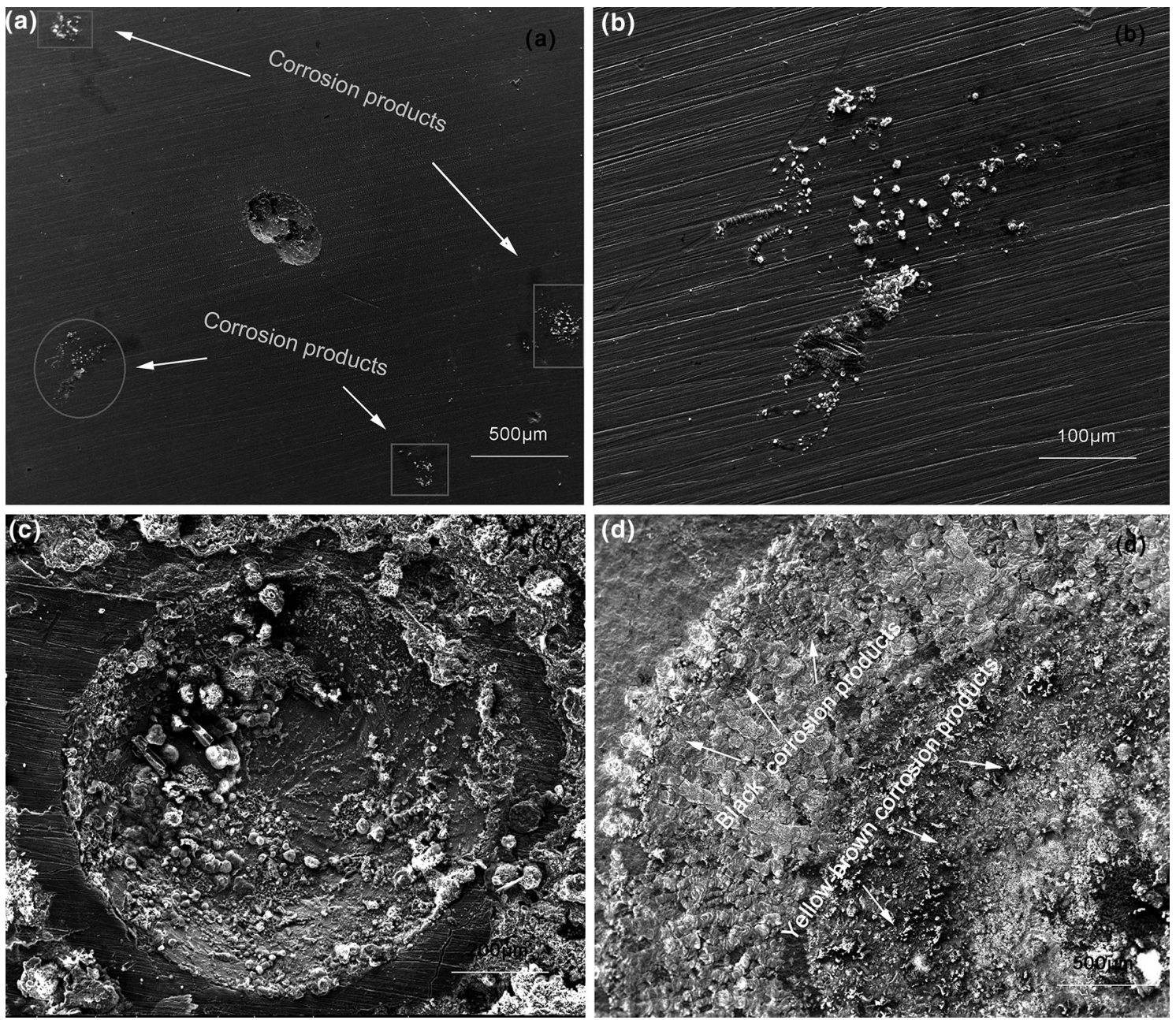

Fig. 9 SEM micrographs of corrosion products under coating: a 140 days after immersed in uncarbonated SPS; $\mathbf{b}$ enlarged view of corrosion product of a; c 10 days after immersed in carbonated SPS; $\mathbf{d} 100$ days after immersed in carbonated SPS

$\mathrm{Fe}^{2+}$ cations produced in reaction (8) were hydrolyzed and oxidized with acidification according to some of the following reactions (9-12). The corrosion products that generated by these reactions were the $\mathrm{FeCl}_{2} \cdot 4 \mathrm{H}_{2} \mathrm{O}$, 
$\mathrm{Fe}_{2}(\mathrm{OH})_{3} \mathrm{Cl}$ and $\mathrm{FeOOH}$, which were validated in the XRD pattern shown in Fig. 10a.

$$
\begin{aligned}
& 4 \mathrm{Fe}^{2+}+\mathrm{O}_{2}+6 \mathrm{H}_{2} \mathrm{O} \rightarrow 4 \mathrm{FeOOH}+8 \mathrm{H}^{+}, \\
& \mathrm{Fe}^{2+}+2 \mathrm{Cl}^{-}+4 \mathrm{H}_{2} \mathrm{O} \rightarrow \mathrm{FeCl}_{2} \cdot 4 \mathrm{H}_{2} \mathrm{O}, \\
& 2 \mathrm{Fe}^{2+}+\mathrm{Cl}^{-}+3 \mathrm{H}_{2} \mathrm{O} \rightarrow \mathrm{Fe}_{2}(\mathrm{OH})_{3} \mathrm{Cl}+3 \mathrm{H}^{+} .
\end{aligned}
$$

Reactions (9-11) led to the increased content of $\mathrm{H}^{+}$ ions, which promoted the dissolution of iron. Furthermore, the products of $\mathrm{Fe}^{2+}$ and $\mathrm{H}^{+}$ions need negatively charged ions to preserve the charge neutrality, resulting in more $\mathrm{Cl}^{-}$ ions transported to the corroded sites. Both of them increased the concentration of ferrous chloride in the corrosion products. The schematic diagram is shown in Fig. 11b. And the degradation mode in uncarbonated SPS, together with the reconstituted region of oxide film, is schematically displayed in Fig. 11a.

After the specimen with the pinhole defect of $800 \mu \mathrm{m}$ in diameter immersed in uncarbonated SPS for 50 days, the straight line with a slope closed to $45^{\circ}$ appeared in the Nyquist plots. And then the feature also appeared in Nyquist plots of the specimens with the pinhole defect of 500 and $200 \mu \mathrm{m}$ in diameter after immersed for 140 and 185 days shown in Fig. 12a. It was attributed to the localized corrosion formed between coating and substrate, which was confirmed by morphology of the steel after removing the coating as shown in Fig. 9a and schematic diagram in Fig. 13a. An enlarged view of the corrosion site in the circle is shown in Fig. 9b. The reaction was controlled by ions diffusion due to the nano-scale crevice. In this period, the $\mathrm{Cl}^{-}$ions enriched in somewhere that corrosion cells were established. EDS analysis showed that the atomic percentage of chloride ions in the corrosion products and substrate surface was $4.78 \%$ and $0.78 \%$, respectively. Meanwhile, the immersion time at which straight line appeared increased with the decreased defect size, which might be attributed to the increased diffusion speed of ions though the pinhole from bulk situation. Three maxima were observed in the phase angle plot shown in Fig. 12b. The equivalent electrical circuit was used to fit the measured data shown in Fig. $4 \mathrm{c}$. The $R_{\mathrm{ct}}$ and $\mathrm{CPE}_{\mathrm{dl}}$ corresponded to the capacitance and resistance of the double layer of the localized corrosion under coating.

Meanwhile, the EIS of specimens immersed in carbonated SPS was similar to that in uncarbonated SPS. The straight line and three frequency-dependent time constant appeared as shown in Fig. 12c, d. When the coating was removed, there were two different corrosion sites on the steel surface. In the yellow-brown round at the center, the corrosion product was $\mathrm{Fe}_{2} \mathrm{O}_{3} \cdot \mathrm{H}_{2} \mathrm{O}$ as confirmed by XRD pattern shown in Fig. 10b. The outer side of round was a black ring, where the chemical composition was the same as the products produced by crevice corrosion at the second stage. The corrosion products of $\mathrm{FeCl}_{2} \cdot 4 \mathrm{H}_{2} \mathrm{O}$ and $\mathrm{Fe}_{2}(-$ $\mathrm{OH})_{3} \mathrm{Cl}$ produced by reactions (10) and (11) were re-oxidized to form $\mathrm{Fe}_{2} \mathrm{O}_{3} \cdot \mathrm{H}_{2} \mathrm{O}$, as shown in the following reactions:

$$
\begin{aligned}
2 \mathrm{FeCl}_{2} \cdot 4 \mathrm{H}_{2} \mathrm{O}+\frac{1}{2} \mathrm{O}_{2} \rightarrow & \mathrm{Fe}_{2} \mathrm{O}_{3} \cdot \mathrm{H}_{2} \mathrm{O}+4 \mathrm{Cl}^{-}+4 \mathrm{H}^{+} \\
& +5 \mathrm{H}_{2} \mathrm{O}
\end{aligned}
$$

$\mathrm{Fe}_{2}(\mathrm{OH})_{3} \mathrm{Cl}+\frac{1}{2} \mathrm{O}_{2} \rightarrow \mathrm{Fe}_{2} \mathrm{O}_{3} \cdot \mathrm{H}_{2} \mathrm{O}+\mathrm{Cl}^{-}+\mathrm{H}^{+}$.

A white metallic appearing at the area that was adjacent to the black ring, turned violet when treated with a phenolphthalein indicator, suggesting that the $\mathrm{pH}$ of the delaminated area was between 10 and 11 . These characteristics suggested that the cathodic half-cell reaction happened in this region, and followed the reaction (5). And

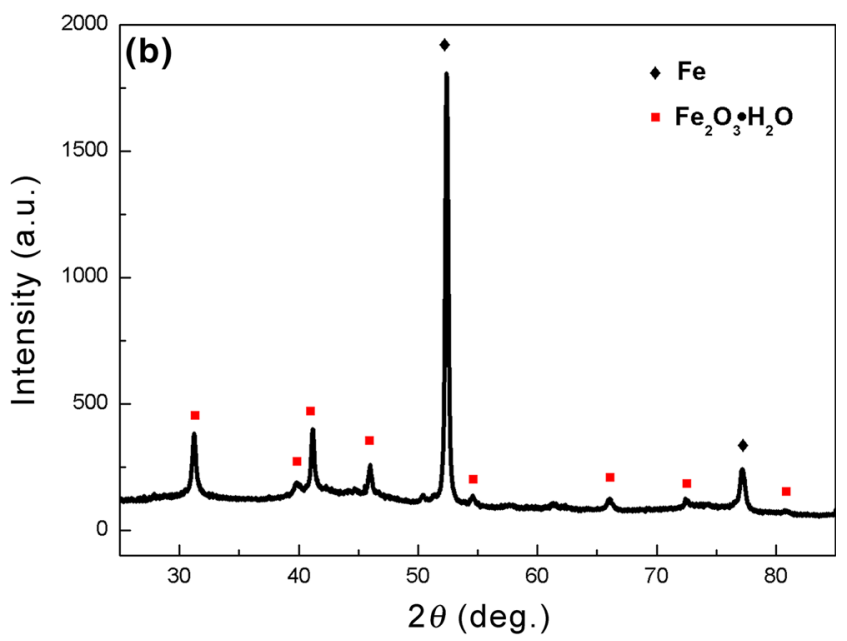

Fig. 10 XRD patterns of corrosion products: a black products; $\mathbf{b}$ yellow-brown products 


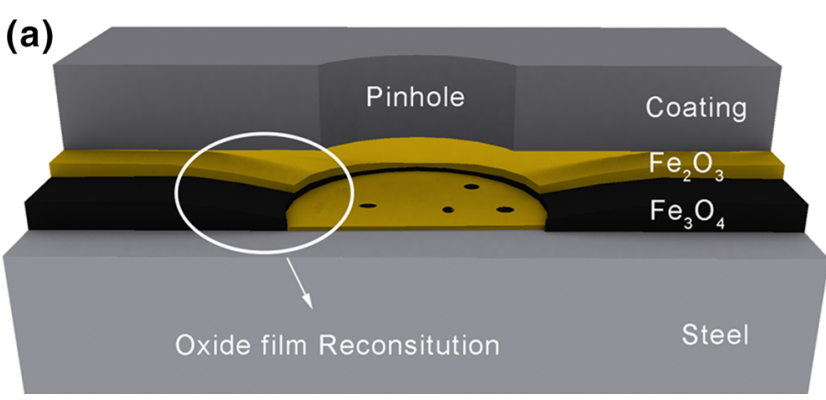

(b)

Fig. 11 Schematic of two behavior modes for defected ECR at the second stage: a uncarbonated SPS; b carbonated SPS
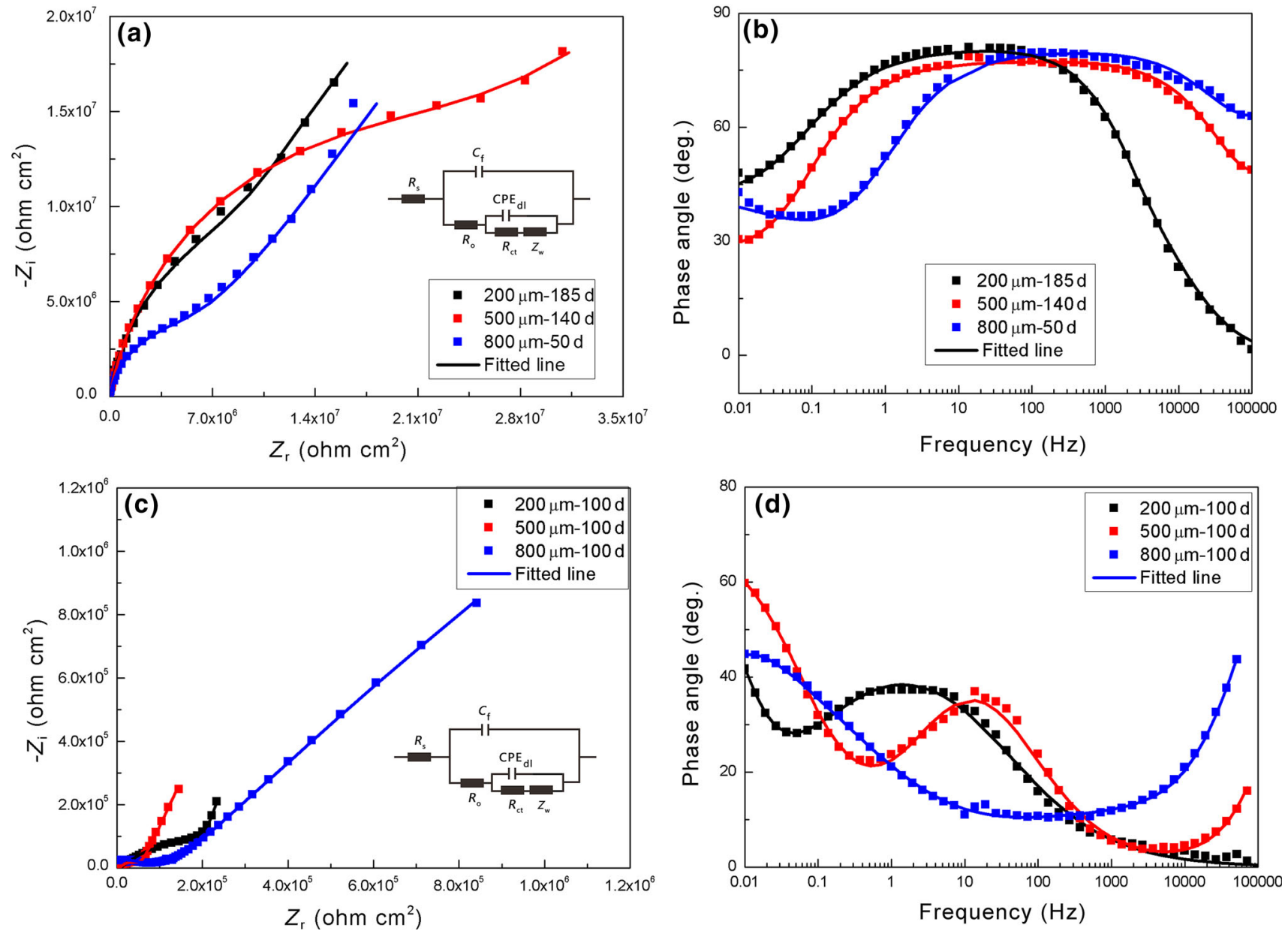

Fig. 12 Nyquist $(\mathbf{a}, \mathbf{c})$ and Bode $(\mathbf{b}, \mathbf{d})$ plots of defected ECR in uncarbonated $(\mathbf{a}, \mathbf{b})$ and carbonated $(\mathbf{c}, \mathbf{d})$ SPS and corresponding fitting results of EIS data at third stage

the corroded areas continued to expand outward. The schematic diagram is shown in Fig. 13b.

The impedance of capacitance element $Q(\mathrm{CPE})$ in this work was given by $Z_{\mathrm{CPE}}=1 / Q_{(j w)^{n}}$, where $Z_{\mathrm{CPE}}$ is capacitive reactance, $w$ is angular frequency, $j$ is the unit of imaginary number, $n$ was the CPE exponent. The CPE would be pure capacitance when $n=1$, while it will be pure resistance when $n=0$. $Q$ was called as CPE when $0.5<n<1$, and it prevails under conditions of surface heterogeneity.

In the later stages of pinhole-defected ECR immersed in uncarbonated SPS, the low-frequency $(f=0.01 \mathrm{~Hz})$ impedance modulus $\left(|Z|_{0.01} \mathrm{~Hz}\right)$ decreased continuously with immersion time as shown in Fig. 14. Fitting $|Z|_{0.01 \mathrm{~Hz}}$ with the data of immersion time by linear regression, we found that the curve of $|Z|_{0.01 \mathrm{~Hz}}-t$ followed the power exponent equation: 


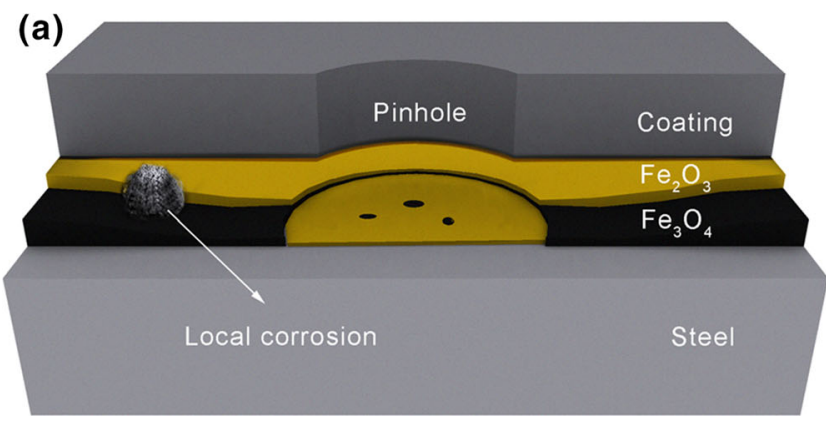

(b)

Fig. 13 Schematics of corrosion behavior modes for defected ECR at the third stage: a uncarbonated SPS; $\mathbf{b}$ carbonated SPS
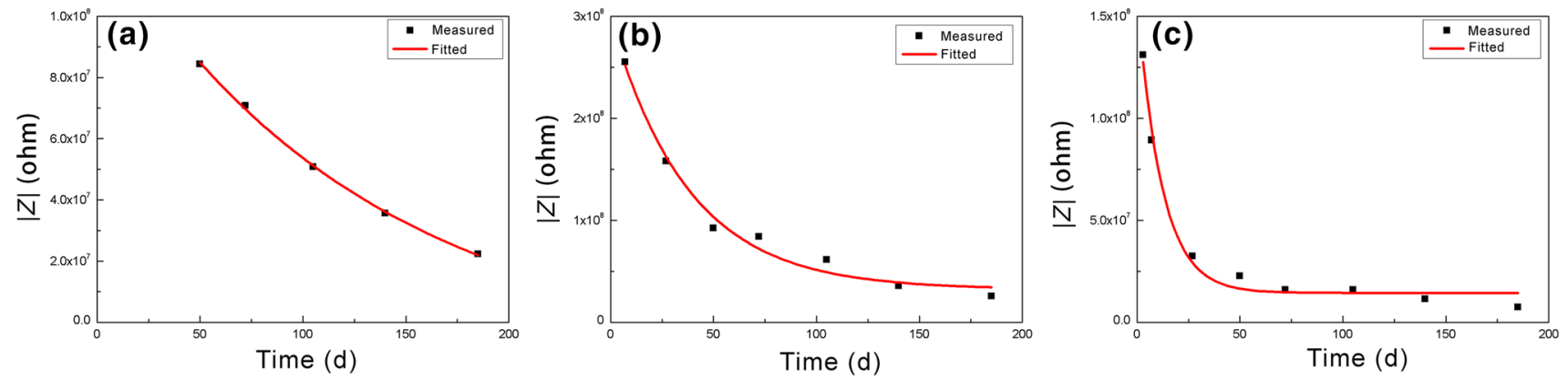

Fig. $14 \mathrm{IZl}_{0.01 \mathrm{~Hz}}$ of different size of defected ECR with immersion time in uncarbonated SPS: a $200 \mu \mathrm{m} ; \mathbf{b} 500 \mu \mathrm{m}$; c $800 \mu \mathrm{m}$

Table 2 Parameters of power exponent equation

\begin{tabular}{lllrl}
\hline Size $(\mu \mathrm{m})$ & $A(\Omega)$ & $B(\Omega)$ & $p$ & $r^{2}$ \\
\hline 200 & $1.14 \times 10^{7}$ & $1.43 \times 10^{8}$ & 127 & 0.998 \\
500 & $3.24 \times 10^{7}$ & $2.64 \times 10^{8}$ & 38 & 0.980 \\
800 & $1.44 \times 10^{7}$ & $1.46 \times 10^{6}$ & 12 & 0.985 \\
\hline
\end{tabular}

$|Z|_{0.01 \mathrm{~Hz}}=A+B / e^{\frac{t}{p}}$,

where $t$ is immersion time and $A$ and $B$ are constants. When $t$ approaches $0,|Z|_{0.01 \mathrm{~Hz}}=A+B$, and $|Z|_{0.01 \mathrm{~Hz}}=A$ as $t$ approaches infinity. $r^{2}$ is the goodness of fit, $p$ is the incubation period of corrosion under the coating immersed in uncarbonated SPS, and it decreased with the increased pinhole size. The values of parameters are summarized in Table 2.

\section{Conclusions}

The corrosion behaviors of pinhole-defected ECR immersed in uncarbonated and carbonated SPS of seawater concrete have been explored, respectively. The results indicated that corrosion behavior of ECR with pinhole defect includes three stages, and the following conclusions can be obtained:
1. In the first stage, the substrates within the pinhole defect were passivated and corroded after immersed in uncarbonated and carbonated SPS respectively, because of the competition adsorption between chloride and hydroxyl ions at the pinhole sites.

2. The oxide film that produced on the substrate by preheating was reconstituted under the coating immersed in uncarbonated SPS in the second stage, accompanying with the decrease of the defect density and the thickness of the oxide film. Meanwhile, crevice corrosion happened on the substrate around pinhole defect in this stage, when the specimens immersed in carbonated SPS. Cathode half-cell reactions occurred in the vicinity of the edge of the pinhole defect, and the corrosion products of anodic sites were $\mathrm{FeCl}_{2} \cdot 4 \mathrm{H}_{2} \mathrm{O}$, $\mathrm{Fe}_{2}(\mathrm{OH})_{3} \mathrm{Cl}$ and little $\mathrm{FeOOH}$.

3. Localized corrosion apparently took place under the coating a few millimeters around the pinhole defect in the third stage, due to the presence of a large quantity of $\mathrm{Cl}^{-}$ions enriched in the corrosion sites immersed in uncarbonated SPS. Ferrous salts produced in the second stage were re-oxidized to $\mathrm{Fe}_{2} \mathrm{O}_{3} \cdot \mathrm{H}_{2} \mathrm{O}$ with the prolongation of immersion time in carbonated SPS.

4. In the later stage of the specimens in uncarbonated SPS, $|Z|_{0.01 \mathrm{~Hz}}$ decreased continuously with the power exponent equation: $|Z|_{0.01 \mathrm{~Hz}}=A+B / e^{\frac{t}{p}}$, the parameter $p$ could be used as the incubation period of corrosion 
under the coating immersed in uncarbonated SPS, and it decreased with the increased size of pinhole defects.

Acknowledgements This work was supported financially by the Strategic Precursor Research Program of the Chinese Academy of Sciences (No. XDA13040500).

\section{References}

[1] N. Takeda, N. Otsuki, Concr. J. 54, 525 (2016)

[2] T. Nagata, N. Otsuki, T. Nishida, H. Ohara, Cem. Sci. Concr. Technol. 67, 495 (2013)

[3] A.M. Zayed, A.A. Sagues, Corros. Sci. 30, 1025 (1990)

[4] S.G. Dong, B. Zhao, C.J. Lin, R.G. Du, R.G. Hu, Constr. Build. Mater. 28, 72 (2012)

[5] A.A. Sagues, Dissertation, University of South Florida (1994)

[6] R.E. Weyers, P.E. Charles, M.C. Wheeler, Diss. Abstr. Int. 63, 3825 (2002)

[7] A.A. Sagues, H.M. Perez-Duran, R.G. Powers, Corrosion 47, $884(1991)$

[8] S.C. Kranc, A.A. Sagues, F.J. Presuelmoreno, ACI Mater. J. 99, $51(2002)$

[9] R. Kessler, R.G. Powers, A.A. Sagues, Corrosion 1, 642 (2001)

[10] H.L. Jr, W. Wang, L. Igetoft, Prog. Org. Coat. 11, 19 (1983)

[11] W. Funke, Prog. Org. Coat. 9, 29 (1981)

[12] C. Zhong, X. Tang, Y.F. Cheng, Electrochim. Acta 53, 4740 (2008)

[13] A.Q. Fu, Y.F. Cheng, Corros. Sci. 51, 914 (2009)
[14] C.F. Dong, A.Q. Fu, X.G. Li, Y.F. Cheng, Electrochim. Acta 54, 628 (2009)

[15] T. Nguyen, J.W. Martin, JCT Res. 1, 81 (2004)

[16] Y. Song, C. Du, X. Li, Int. J. Miner. Metall. Mater. 13, 37 (2006)

[17] W. Zhang, J. Wang, Y.N. Li, W. Wang, Acta Phys. Chim. Sin. 26, 2941 (2010)

[18] Y. Chen, W. Zhang, Q. Wang, J. Wang, J. Chin. Soc. Corros. Prot. 37, 322 (2017)

[19] D.A. Hausmann, Mater. Prot. 6, 19 (1967)

[20] V.K. Gouda, Br. Corros. J. 5, 198 (2013)

[21] V. Leelalerkiet, J.W. Kyung, M. Ohtsu, M. Yokota, Constr. Build. Mater. 18, 155 (2004)

[22] M. Ohtsu, T. Yamamoto, Constr. Build. Mater. 11, 395 (1997)

[23] C. Exartier, S. Maximovitch, B. Baroux, Corros. Sci. 46, 1777 (2004)

[24] F. Mansfeld, J. Appl. Electrochem. 25, 187 (1995)

[25] G.Z. Meng, C. Zhang, Y.F. Cheng, Corros. Sci. 50, 3116 (2008)

[26] A.Y. Lee, D.M. Blakeslee, C.J. Powell, J.R. Rumble, Data Sci. J. 1, 1 (2006)

[27] W.B. Mi, E.Y. Jiang, H.L. Bai, J. Phys. D 42, 105007 (2009)

[28] T. Fujii, F.M.F. De Groot, G.A. Sawatzky, F.C. Voogt, T. Hibma, Phys. Rev. B 59, 3159 (1999)

[29] M. Aronniemi, J. Sainio, J. Lahtinen, Surf. Sci. 578, 108 (2005)

[30] L.V. Taveira, M.F. Montemor, M.D.C. Belo, M.G. Ferreira, L.F.P. Dick, Corros. Sci. 52, 2831 (2010)

[31] N.B. Hakiki, S. Boudin, B. Rondot, M.D.C. Belo, Corros. Sci. 37, 1809 (1995)

[32] D.G. Li, Y.R. Feng, Z.Q. Bai, M.S. Zheng, Chin. J. Appl. Chem. 25, 1007 (2008)

[33] G.W. Walter, Corros. Sci. 26, 681 (1986) 